\title{
MODELLING THE POSITIVE FEEDBACK MECHANISM OF A KARST AQUIFER USING SURFACE RECONSTRUCTION
}

\author{
KYFFIN K. BRADSHAW \& TANE S. RAY \\ Department of Computer Science, Mathematics \& Physics, University of West Indies Cave Hill Campus, \\ Barbados.
}

\begin{abstract}
Karst conduit network modelling is particularly difficult because the location of the conduits within an aquifer is often unknown. To address this, many mathematical models of karst aquifers use stochastically simulated conduit networks to try to extract certain geometrical and hydraulic connectivity properties that may prevail within the aquifer. Such idealized representations of a karst aquifer do not adequately represent the positive feedback mechanism that exists between the distribution of hydraulic head and the growth of the solution conduits that determine the geometry and the interconnectedness of the resulting conduit network. In this paper, Poisson surface reconstruction is presented as a simple method for constructing a realistic model of a karst aquifer by simulating the positive feedback mechanism between dissolution and flow. Direct application of the Poisson technique to a tropical karst limestone aquifer of the island of Barbados highlights how the complete conduit geometry and the feedback mechanism of a real aquifer system may be interpolated. The result suggests that applying surface reconstruction to a good calibrated point cloud sampling taken from an aquifer itself is an efficient methodology for generating realistic karstic networks. Additionally, Poisson surface reconstruction replicates an aquifer without directly solving complex hydrogeological and speleological equations and oversimplifying the hydrogeological and geological complexities of a karst environment in the way that hypothesized conduit network models do. As a result, it is believed that this conceptual model provides a utility for characterizing a karst aquifer in terms of the well-established theoretical foundations of the surface reconstruction problem even when the input data is sparse.
\end{abstract}

Keywords: conceptual model, conduit network, feedback mechanism, Poisson surface reconstruction.

\section{INTRODUCTION}

Modern computer graphics and technologies have significantly improved the modelling and digital representations of real-world phenomena. Recently, there has been a proliferation of synthetic karst aquifer models aimed at representing the geologic architecture of these aquifers. However, the problem with these models is that they represent karst conduits as stochastically simulated conduits embedded in a rock matrix [1-4]. In these models, stochastically generated conduit networks are combined with fracture and rock porosity models to create a numerical model of a karst system. As a result, this type of formulation is used to theoretically examine the possible ways conduit network geometry and connectivity might influence or impact upon karst groundwater dynamics [2-3, 5-8]. The disadvantage with the synthetic aquifer model is that it adds heterogeneity to the model using a stochastic process. As reported by Filipponi et al. [9], natural karst conduits develop along discrete preferred surfaces, and therefore, their spatial distribution should neither be considered uniform nor random, but rather as a fixed, well-ordered 3D structure. Hence, randomly generated conduit networks cannot systematically predict at a regional scale the true influential potential of the distribution, shape, density, and connectivity real-world conduits have on groundwater storage and circulation. Therefore, stochastic synthetic aquifer models are impractical for predicting the spatial patterns of conduits in their natural environment because they do not provide detailed information of the three-dimensional (3D) extent of the aquifer that is necessary to acquire a better understanding of the environmental conditions they are intended to 
depict [8]. To improve upon this requires efficient ways to generate plausible real-world conduit networks that are conditioned to field data [7]. Bonacci et al. [10] reported that understanding the unique structural characteristics of karst aquifers requires the development of original, yet simple karst investigation techniques capable of representing the role that dynamic, structural, and transport connectivity has on groundwater storage and circulation within the aquifer unit. However, [3,11-13] suggest that this level of detail requires largescale mapping of the physiographic and hydrologic features associated with the particular karst environment. In [14], caves are described as ideal locations for entering a karst aquifer and directly witnessing water moving within parts of the active conduit network. For young limestone of uplifted carbonate islands like Barbados, speleogenesis is confined to regions where dissolution is concentrated enough to form caves. According to Taboroši et al. [31], voids that permit entry are prevalent in areas where dissolution was focused by hydrologic or geologic boundaries. In [31], the boundaries within the vadose zone constitute lithologic contacts or structural discontinuities that channel flow. In contrast, the boundaries in the phreatic zone are hydrologic contacts. This speleogenesis perspective accounts for the self-organizing nature of conduit networks and the positive feedback mechanism between dissolution and flow. According to De Rooij and Graham [7], the speleogenetic model is a promising aquifer modelling technique that may allow for the realization of hydrologically and geologically consistent karstic networks because it simulates the positive feedback loop between dissolution and percolation through the rock matrix. Despite this potential, the model is considered computationally intensive and difficult to condition to field data. Some researchers think that this approach should not be a first choice for karst network modelling purposes [15-17], even though other studies have successfully mapped karstic networks using the speleogenetic formulation [32]. In this study, it is shown that applying surface reconstruction to Barbados' karst limestone aquifer results in a modelling technique that is similar to the speleogenetic model in its potential for interpolating the feedback mechanism and the hydrogeological structure of a karst aquifer. It is assumed in this investigation that the theoretical foundations of surface reconstruction make it a good first approximation technique for estimating the spatial heterogeneity of a karst conduit system and depicting the existence of the positive feedback mechanism associated with the underlying structural character of the aquifer. Unlike the speleogenesis model, surface reconstruction does not require initiation with an initial proto-conduit network and does not make the same quasi-steady-state approximations as the speleogenesis model. In [7], the speleogenesis process is explained in terms of a sequence of steady-state flow and steady-state reactive-transport computations. For this proof-of-concept study, surface reconstruction differs from the speleogenetic model because it is assumed that the conduit network geometry can be simulated solely from point clouds and hence requires no complex hydrogeological and hydrologic data inputs like the speleogenesis process. The underlying assumption is that fractures on the orders of kilometres in heterogeneous rocks may be described as fractal sets. These sets form structures that are similar to critical percolation clusters with fractal dimensionality. Therefore, when focusing on the connectivity or connectedness of a system, the 'backbone' of the medium is all that needs to be examined [36]. The backbone is defined as the part of the percolation cluster that sustains non-zero flow. It is described as a fractal object with known dimensions. It also obeys a scaling law and may be estimated through simulation [37-41]. Percolation models may be used for examining cluster, backbone, and elastic backbone structures in multiple invasion percolation problems. These models examine the sites through which flow passes and how loops of the structures behave. When the sites through which the flow passes almost 
disappear, the cluster has achieved a high degree of connectivity. The assumption is made that the distribution of the conduits created in formation of the flow domain of the aquifer forms a structure that may be comparatively similar to the lattice nodes contained in a percolation backbone. Therefore, restricting including in the analysis the notion of the backbone may, for the purposes of this study, potentially circumvent the challenge that comes with collecting data from boreholes. Exploration of boreholes is an important technique used for evaluating deep positions in karst [42]. However, this technique provides information that is limited to an area within the vicinity of the boreholes and, consequently, sometimes leads to cases where the drilled hole just misses a major cave or fracture. Therefore, it is believed that by treating a karst aquifer as though it behaves like a percolating system and considering the backbone as a major flow component mitigates having to estimate the probability that any of the boreholes used missed a conduit. Assuming the existence of a hydraulically connected backbone ensures that it would be still possible to capture the true hydraulically connected nature of Barbados' karst conduits and their conduit-associated drainable-storage, even if a drilled hole missed a major conduit.

To advance the idea that treating the modelling of a karst aquifer like a classic surface reconstruction problem has the potential of modelling the feedback mechanism, the concept behind surface reconstruction is briefly discussed. The surface reconstruction process converts discrete measured point cloud data taken from an object into a 3D representation of the sampled object. Figure 1 shows the regions of the island from which the point cloud data was

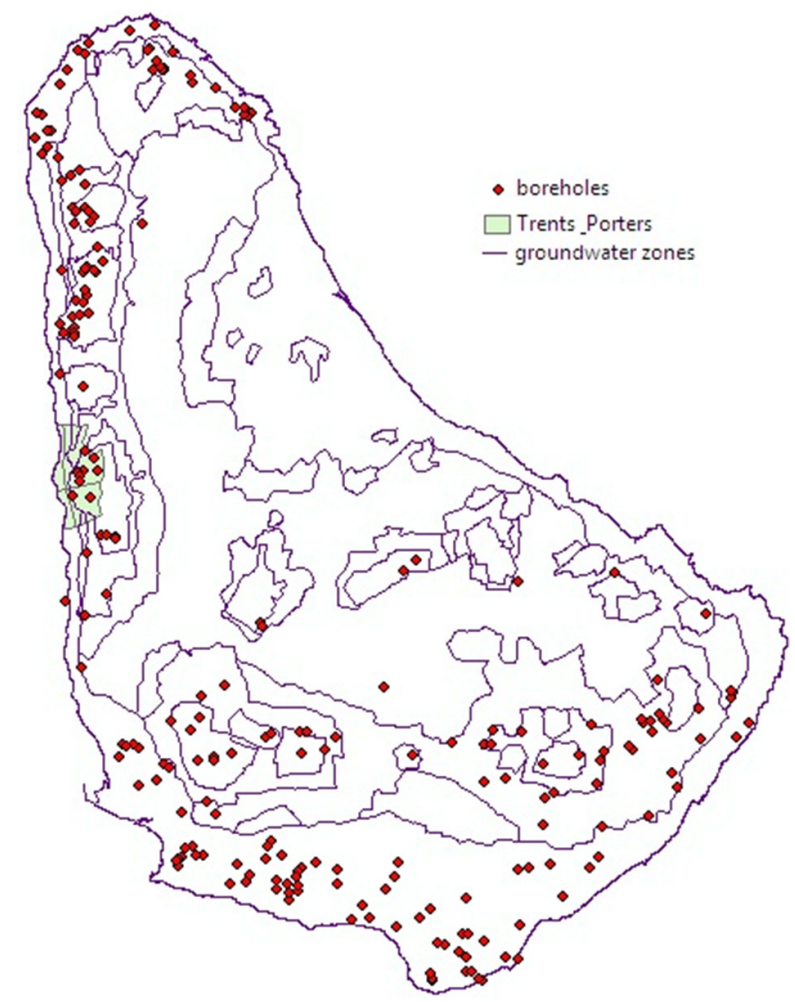

Figure 1: Point cloud data collection points (adapted from ArcView shape files provided by the Caribbean Institute for Meteorology and Hydrology). 
collected. In this sense, surface reconstruction may be considered a type of physical modelling process. In physical modelling, models are constructed in a 3D computer environment using actual physical parameters from the field to give predictions of the spatial positions of conduits. These types of models are considered superior to other models because they use actual field data as opposed to using idealized premises as in the case of global parameter optimization, stochastic formulations, finite element numerical techniques, and hydrogeological mathematical modelling.

For the purposes of this investigation, it is assumed that the surface reconstruction formulation is a type of physical model with an added process-imitating and structure-imitating component. Process-imitating approaches attempt to mimic the speleogenesis process underlying the conduit formation by simulating the self-organizing nature of the conduit that is associated with the feedback mechanism via an iterative process [7]. In contrast, structure-imitating approaches try to recover the structure of conduit networks statistically.

Reproducing conduit network topology, connectivity, tortuosity, and hydraulic conductivity from the perspective of the classic surface reconstruction problem has not been investigated before. Consequently, the objective of this study is to provide as a proof of concept how applying the surface reconstruction problem to a karst environment is capable of generating environmentally consistent subsurface images of the internal architecture of a karst aquifer by interpolating the feedback mechanism. Generally, a surface reconstruction problem is defined as follows: a set of sample points assumed to lie on or near an unknown surface create a surface model approximating. A limitation with using surface reconstruction is that it cannot guarantee construction of the sampled surface precisely. This happens because information about the sampled surface is through a finite set of sample points. However, if the sampling density is sufficiently large, the output surface model tends to be topologically consistent and converges to the original surface. Under conditions where the input data is highly noisy and does not have good distribution and density, the surface reconstruction algorithm produces incorrect results. Therefore, reconstruction methods are dependent on the way they are applied and on the type of algorithm used for the reconstruction. For a reconstruction method to be valid, it must infer the correct geometry, topology, and features of the object from which the point cloud sample was taken.

Similar to [7], the investigation presented in this study does not consider, for example, pressure transfer and water exchanges between lower permeability volumes and conduits, so as to avoid computational difficulties in simulating transitions between open and closed conduit flow. Unlike [7], the assumption is made that the topology does not remain constant. It is believed that the point cloud data used for the reconstruction problem innately accounts for natural changes in topology. The reconstruction algorithm presented works on the notion of unorganized point clouds. These types of algorithms have no information on the input data other than their spatial position. The problem with this is that if the input points are not uniformly distributed, the formulation from unorganized point clouds fails. Hence, for this study, the input point cloud is assumed to be in the 'general position'. The general position is defined so that in a collection of points, if three points of are not collinear and any other four points of are not co-circular, then the points are in the general position. By assuming the general position ensures that if the positions of three non-collinear points, , and are known in some appropriate coordinate system, then the location of another point may be found in relation to the other three points by the use of triangulation. Triangulation converts the point cloud into a consistent mesh. This process is done by partitioning the input data into simplicies and generates vertices, edges, and faces representing the analysed surface that meet only at shared 
edges. A finite element method is then used to discretize the measured domain. In the reconstruction process, an optimal triangulation is defined by measuring the angles, edge length, height, or area of the elements. The error associated with the finite element approximation in this case relates to the minimum angle of the elements. The idea of using non-collinear points is essentially an approximation to the classical three-point problem encountered in computational geometry. In the three-point problem, if the height of a bed is known at three or more non-collinear points, then it is possible to find the direction of strike and calculate the dip of the bed, provided that the dip is uniform. To further give context to this research, a brief description of the study area is provided in the following section.

\section{THE GEOLOGY AND HYDROGEOLOGY OF BARBADOS}

The island of Barbados, geographically located at latitude and longitude, is a very small coral limestone island that measures long and wide. It has a total area of with the highest elevation being approximately . The limestone formation of Barbados rises as a chain of terraces, slopes, and scarps in the northward, westward, and southward parts of the island as shown in Fig. 2. During the rainy season, the island can have an average rainfall above 140 $\mathrm{mm} / \mathrm{month}$. In the dry season, the average rainfall can be as little as $40 \mathrm{~mm} / \mathrm{month}$.

Approximately $15 \%$ of Barbados forms the Scotland District which is made up of clays, shale, and sandstone. The island features several deep gullies that channel rainwater down to the coast and as a result, the island has very few examples of permanent surface drainage; for

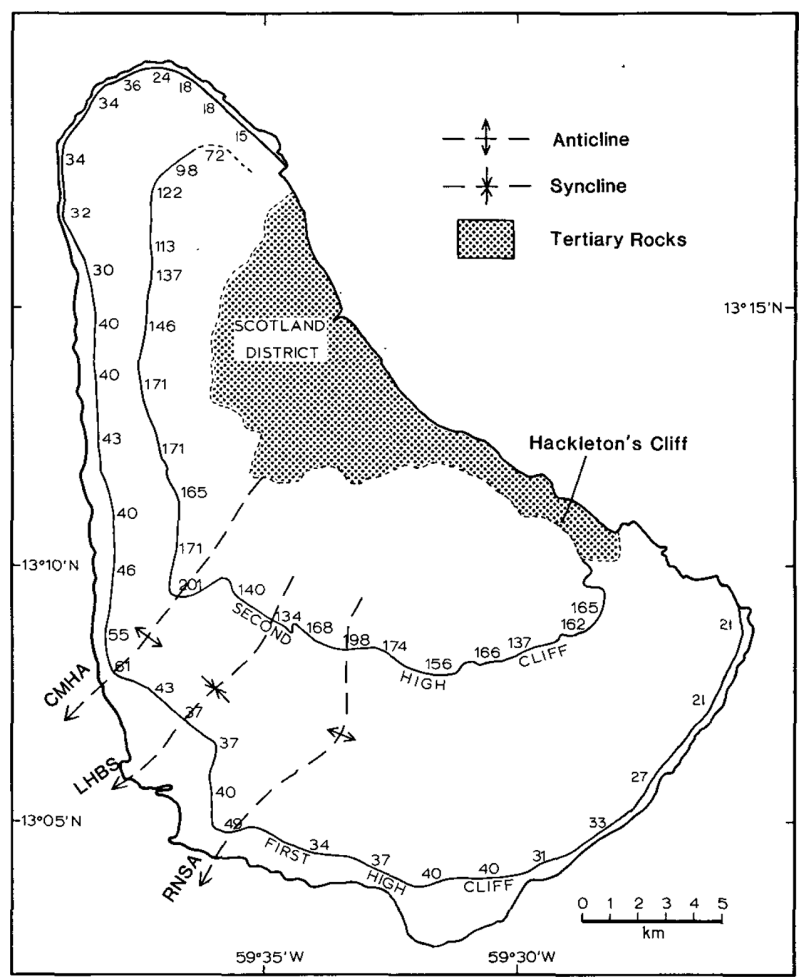

Figure 2: Geology of Barbados (adapted from shape files provided by the Caribbean Institute for Meteorology and Hydrology). 
example, rivers, streams, and springs. All of the few existing rivers, with the exception of the Constitution River, lie within the Scotland District. This is a result of impermeable rock that causes the water to remain on the surface. South of the Scotland District, the landscape dips into the St. George valley; this separates the main limestone areas in the northeast from the lower limestone ridge in the southern portion of the island. These two main terraces are known as the First and Second High Cliff, respectively. Their altitudes vary from around to and approximately beyond the sea level. The eastern side of the island shows no rising terraces. The highest and oldest identified limestone in Barbados is located at the centre of the island. Several sinkholes spread across approximately $\mathrm{km}^{2}$ of the island. Sinkhole density on the island increases with altitude up to an elevation of , but then decreases beyond that point. The spatial distribution of the sinkholes along the western coast of the island falls within and orientation groups and has no specific sinkhole long-axis orientation. However, in the northern part of the island, the sinkholes tend to have a northeast orientation and an orientation class. Since sinkhole development is inextricably linked to groundwater flow, the precise location of sinkholes provides a good guide to the possible existence of channels and caverns within the karst unit. As a result, the northeast trend of the sinkholes on the island suggests that the underlying coral rock fracture and conduits of Barbados have a northeast orientation.

Recharge to the island's aquifer occurs through runoff via high-speed infiltration through sinkholes that exist along areas in the sides of dry valleys. According to Jones and Banner [43], water residence times in the unsaturated or vadose zone can be of the order of minutes to days for water permeating these sinkholes. However, Jones and Banner noted that the residence times relating to diffuse infiltration can occur over a period of days to months. In [43], it was also observed that diffuse recharge was likely to be present above the Second High Cliff of the island. In this region, soil infiltration rates the highest. Also, Jones and Banner [43] found that karst shafts had a higher potential to recharge the aquifer in the form of conduits than the layer of inter-fluvial sinkholes that were characterized by low soil permeability. They thought that karst shafts on the laterals of dry valleys were capable of transmitting high amounts of water to the underground reservoir during short cycles of runoff. As a result, Jones and Banner [43] proposed that groundwater flow channels in the island's aquifer were governed by the topography of the top of an existing aquitard.

About $70 \%$ of the near-surface geology of Barbados is composed of limestone that displays karst effects. This Pleistocene limestone cover of Barbados, which mostly lies above the water table, is locally known as the 'Coral Cap', but is formally referred to as the Coral Rock Formation. This coral cap is karstified and dips towards the west and south in a series of terraces from the highest point of the island. The Coral Cap varies in thickness between and is divided into two hydrologic zones known as the 'stream-water' zone and the 'sheet-water' zone that receives recharge through vertical infiltration or lateral inflows from the upland areas to the east. The sheet-water zone, as illustrated in Fig. 3, is a lens of freshwater in an unconfined aquifer that occupies a narrow zone along the coast. At the base of the Coral Cap, groundwater flows are believed to occur as stream water via an integrated network of underground conduits from the central highland of the island towards the sea. In the stream-water zone, water is thought to percolate through the coral until it reaches the underlying Oceanics. This flow either occurs diffusely or in cave systems. The water table in this region is stated to be approximately below the valley floors and closely tied to the top of the Oceanics. The slope or gradient of the water table depends on the permeability of the coral rock and the amount of percolation. These so-called stream-water channels connect to a coastal meteoric 


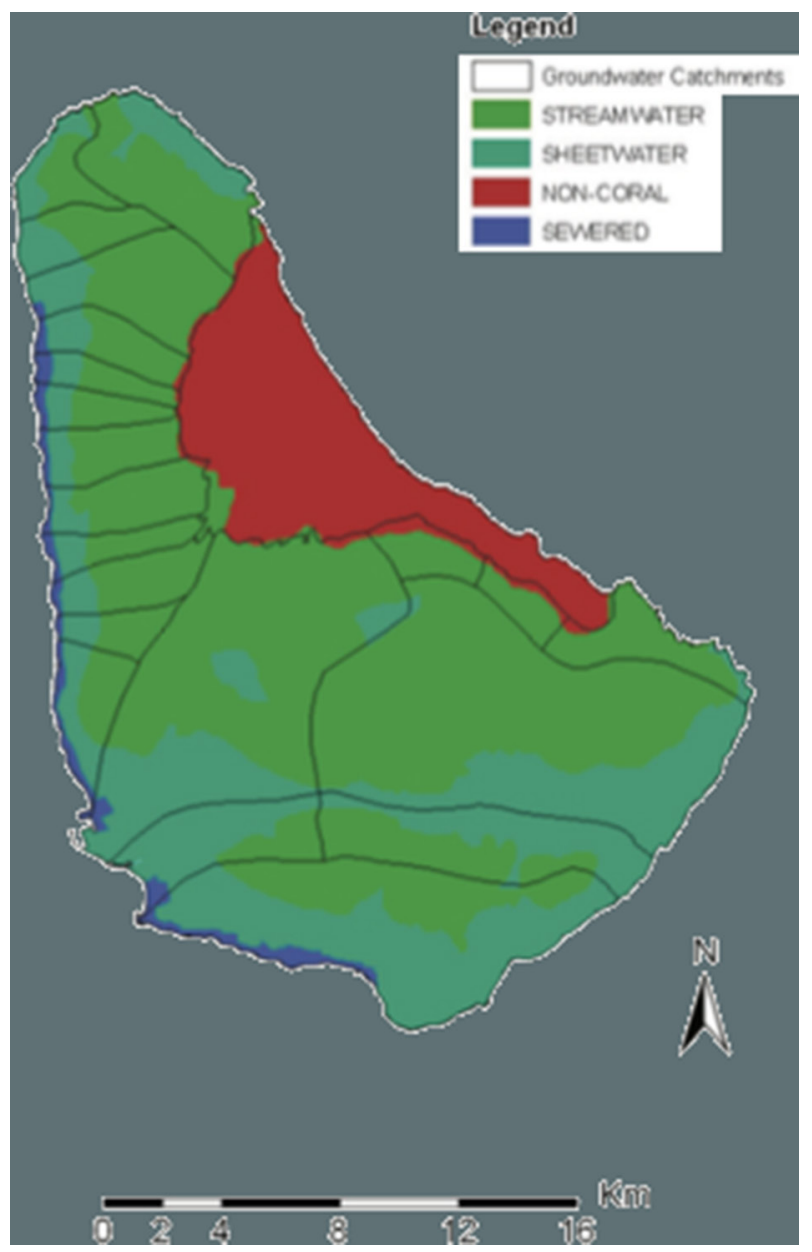

Figure 3: Groundwater distribution of Barbados (adapted from ArcView shape files provided by the Caribbean Institute for Meteorology and Hydrology).

lens at the sea level to form what is locally called sheet-water areas. Near the coast, the interface between the coral rock and the Oceanics dips below the sea level.

The sheet-water zone is confined to the western coastal area and the St. George valley and begins where the surface of the Oceanics is below the sea level. This interface forms the coastal freshwater lens, and where the freshwater lens merges with marine pore fluids, it creates a freshwater-saltwater mixing zone. The coastal freshwater wedge sits on top of the denser marine pore waters. This zone varies in thickness around the island. The thickness varies between 2 and $13 \mathrm{~m}$ seasonally in the Christ Church region of the island. Differences between thicknesses relating to the mixing zone are attributed to shifts in freshwater recharge, tidal and storm-surge pumping, and proximity to the coast. Immense transmissivity associated with the Pleistocene limestone causes the water table of the sheet-water zone to rise to a maximum of $1 \mathrm{~m}$ above the sea level. Usually, the water table in this zone is relatively parallel to and slightly above the sea level. However, at the inland part of the sheet-water zone, the water table reaches below the valley floors. 
Barbados also features five different types of caves: stream caves, flank margin caves, sea caves, mechanical caves, and hybrid caves [20]. The variation of cave systems on the island is highlighted because caves are regarded as ideal places to study geology as they provide much information about the developmental history of the surrounding landscapes. It is these drains that are responsible for the rapid reaction of the karst springs to high rainfall periods and the intricate dispersion of the solutes in the system [11, 25]. However, for the purposes of this study, the stream cave is highlighted. The stream caves on the island are formed by freshwater dissolution. Harrison's Cave along with Cole's Cave, located within the Upper Coral Rock of the island, is known to be the longest and a well-known example of stream caves formed in Barbados. Harrison's Cave, the Animal Flower Cave, Cole's Cave, and the Bowmanston Cave are examples of some of Barbados' conduit networks. Harrison's Cave has developed inside the outcrop of the Upper Coral Rock of the island and measures $2.3 \mathrm{~km}$ in length, with its largest cavern measuring approximately $15 \mathrm{~m}$ high. Cole's Cave, similar to Harrison's Cave, features approximately of branching passages and is recharged via sinkholes and direct input of water upstream. The Bowmanston Cave is approximately $2.4 \mathrm{~km}$ long and $91 \mathrm{~m}$ below the ground level. Several of the caves in Barbados have well-preserved complex coral facies and passage morphologies that are consistent with dissolution processes affiliated with a freshwater lens. The top of the freshwater lens is thought to be a site where there is mixing of unsaturated freshwater zone and saturated freshwater zone. The bottom of the lens, in contrast, is identified as a place of marine water and freshwater infusing. Both these environments are said to be capable of creating renewed dissolutional aggressivity, and at the lens margin, they are superimposed upon each other to create an additive dissolutional effect.

The island's potable water supply comes from groundwater that collects in a shallow 'unconfined' karst limestone aquifer that is about thick. The aquifer is known to have a freshwater lens that is about thick around the region of the Belle pumping station in the Belle aquifer and thins to about close to the southern portions and west coast of the island. There is also a groundwater protection zoning policy in place to protect the public water supply from potential contamination. However, at the time of formulating the policy, pollutant time for bacteriological and chemical pollutants through the aquifer was used to demarcate five protection zones as represented in Fig. 4.

Four out of these five zones are reported to potentially have an adverse effect on the groundwater conditions of the island as zone 5 areas lie downstream and outside of the water collection points of the island. Land use restrictions for zone 5 pertain specifically to coastal zone protection. The seaward flow of fresh groundwater to coastal waters may transport land-generated pollutants to the coastal ecosystems. Zone 1 areas are classified as the most restrictive to physical development. This is because zone 1 is within what is termed the 'cone of influence' of the water supply well. In this zone, there is a -day travel time estimate for viral and bacterial transport between contaminant source and municipal wells. With the current zoning policy, no wastewater is expected to reach a public well within 300 days. This estimated period was thought to be adequate for any contaminating bacteria to die off. At that time, this zoning system was considered effective in protecting the public from indicator diseases such as dysentery and cholera. Zone 2 , which is adjacent to zone 1 , has an estimated -day travel time estimate, and hence is also closely monitored so as to ensure that the groundwater is not contaminated. Again, proximity to the public supply is the reason for such close monitoring. However, zone 2 allows for the use of septic tanks with effluent into a well not exceeding . Zone 3 has an estimated travel time of 5-6 years. No septic tanks are required for 


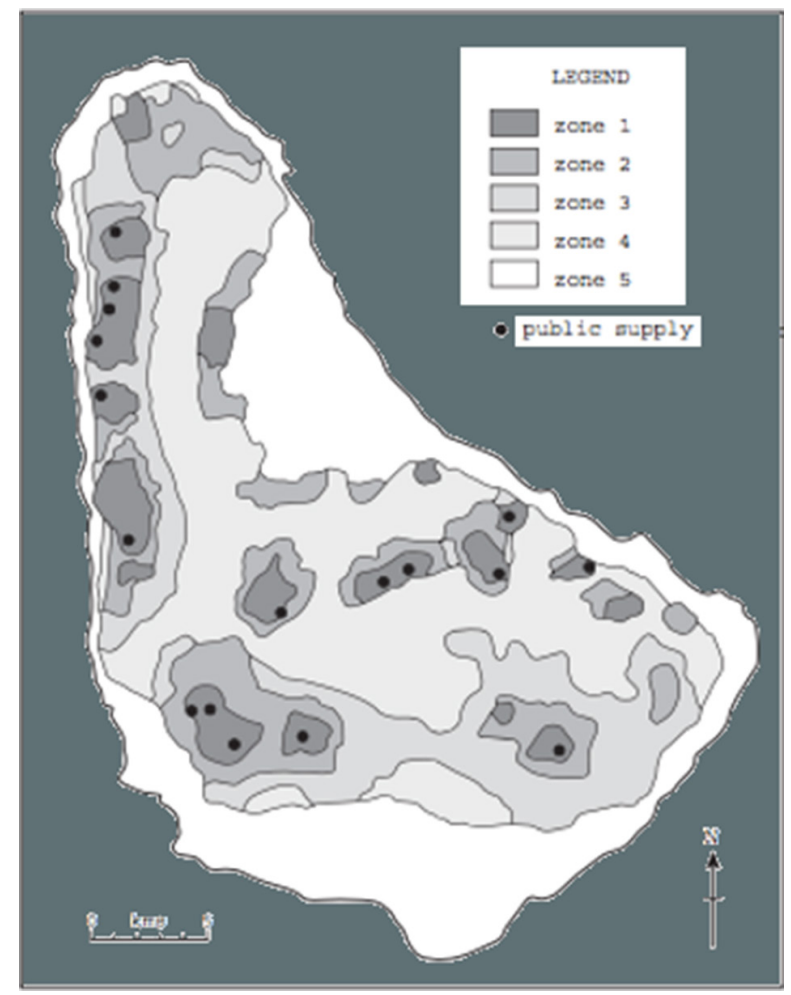

Figure 4: Groundwater zones of Barbados (adapted from ArcView shape files provided by the Caribbean Institute for Meteorology and Hydrology).

zone 3, but wells must be provided for sewage. Zone 4 is considered all high land, and consequently, there are no restrictions placed on domestic wastewater.

The groundwater protection zone concept is one that focuses on restricting land use and human activities in an attempt to limit the danger of groundwater contamination. However, the coverage of the groundwater protection zone is a function of the geology of the aquifer as well as the overall transmissive and fracturing properties of the aquifer. The extent to which the island's potential conduits are connected and developed may have a significant function in the transport and distribution of contaminants across the island's aquifer system and, as a result, may potentially threaten the validity of the current 300-day travel time zoning policy for viral and bacterial transport between contaminant sources and municipal wells. Given the potential for fast pathways with short travel times, viral and bacterial transport may occur more quickly than the stated 300-day travel time.

Subdividing the island of Barbados into five groundwater protection zones was a safety mechanism implemented to ensure that every area of land could be classified according to some protective zone with varying land use restrictions. The principle reason for these varying restrictions is their proximity to public supply wells. However, the value of using groundwater protection zoning in this manner is still widely disputed. It is argued that hydrogeological conditions in karst are so complex that no zoning scheme can truly account for that. According to Doerfliger et al. [34], groundwater protection zoning is often insufficient and, 
consequently, its implementation may be inadequate for different reasons. Counter arguments purport that zoning is adequate for the use as a general framework for developing and implementing groundwater protection policy because it is inaccurate to expect exclusive protection for all groundwater. In addition, it is argued that a zoning strategy is often an important element in ensuring that there is a balance between economic development and aquifer protection. Therefore, zoning is an important component in implementing strategies for groundwater monitoring, making environmental audits of industrial premises, dealing with pollution mitigation within the agricultural advisory system, and, in general, public education [35].

\section{THE MODELLING APPROACH}

The existing groundwater conditions on the island give Barbados a status as one of the most 'water-stressed' Caribbean states [33]. The island is reported to have an availability of less than of freshwater per person per year. And, with Barbados' already high and increasing population density, this available water supply falls below the specified limit for which a country is classified as water scarce. As a result, the island has been given a ranking that places it in the top 15 most water-stressed countries existing to date.

In addition to being water stressed, severe periodic droughts and other phenomena such as saltwater intrusion and submarine groundwater discharge further affect the availability and quality of fresh groundwater on the island. Salinity estimates in groundwater extracted from supply wells across the island could exceed. In response to salinity levels exceeding, the Barbados Water Authority (BWA), which is a government body that is responsible for managing, allocating, and monitoring of the island's water resources, removes the wells from production until the salinity levels decrease. Saltwater movement can occur by the lateral motion of the freshwater-saltwater interface or upconing, which is defined as the precipitous intrusion of saltwater into a freshwater lens from deeper salty zones below pumped wells, upward leakage from deeper salty water-bearing zones, and through the presence of unflushed pockets of relict seawater. Basically, the results of the freshwater-seawater interactions are controlled by the characteristics of the recharge, extent and bounding requisites of the aquifer, spread of the hydraulic conductivities in the system, and the spatial and material changes of these associated parameters.

Inherently, conduits provide hydraulic connectivity between freshwater regions and saline zones. They also influence groundwater storage, recharge, and transmission in an aquifer system. Water resource managers on the island are urgently seeking to address this saltwater intrusion issue. As a result, this research is a part of that effort and focuses on documenting and accurately interpreting the hydrologic environment of Barbados' karst aquifer. To do this, the island's aquifer may have to be investigated in terms of its protective cover, epikarst, infiltration conditions, and karst network development. Of these four karst aquifer attributes, this study concentrates specifically on the spatial geometry of island's conduits and the corresponding 3D matrix. It was hypothesized that given the small landmass of Barbados and the general mimicking characteristic of the water table, if surface reconstruction is applied to a data sample from the aquifer, then it may be possible to produce real 3D images of the island's karst conduits in their natural environment, once mimicking was actually taking place. Generally, the water table usually will copy the topographic contours of the land surface above it. However, it is understood and accepted that the water table does not always reflect the topography or even the upward and downward slants of the land above it.

Despite this possibility, it is believed that the technique used for this investigation is still very promising in its potential for providing a better understanding of the flow and storage of 
a karst aquifer because it innately depicts the system in terms of its three porosity elements by defining the model in terms of Laplace-Beltrami operators used in Poisson surface reconstruction. The eigenfunction of the Laplace-Beltrami operator has a well-established theoretical background and provides a set of real valued functions that give interesting insights into the structure and morphology of shape. Laplace-Beltrami operators are known for their ability to allow for a natural multiresolution structure on the function space that is independent of the mesh structure, thereby allowing for a simple way to solve the Poisson equation. Solving the Poisson equation is a fundamental step in image and mesh processing applications. From this perspective, the modelling approach for this research may be surmised as computing and solving the Poisson equation over a point cloud data set taken from Barbados' karst limestone aquifer. Equally, it may be interpreted as applying the discrete Laplace-Beltrami operators for shape analysis and segmentation to a karst system for basic and generic aquifer characterization. Due to the unavailability of comparative 3D models of Barbados' limestone aquifer, the performance of the proposed model could only be evaluated against the known environmental characteristics associated with the young limestone of uplifted carbonate islands like Barbados. For example, it is known that conduit development in lateral flow from a recharge boundary to an outlet is typical for unconfined karst aquifer settings. Also, a typical karst aquifer features a hierarchical conduit network in which a positive feedback mechanism allows larger conduits to grow faster than and in favour over the smaller ones. Despite the fact that such comparisons may suffice for this study, it is acknowledged that more robust and detailed validation of the proposed model is required, and hence, this is planned for future studies. Ultimately, the modelling approach presented in this paper is a conceptualization method for generating conduit geometries of a karst aquifer with manageable input data demand and minimal computational effort. Initially, focusing on this area was thought to be a good starting point to tackling two of the wider problems in karst research. First, the knowledge about the complete geometry of conduits and their topology remains spatially limited and uncertain. And, secondly, as highlighted in [11], conventional methods for studying the subsurface in porous regions are often inadequate for karst, as they do not capture the true nature of the karst. Hence, multidisciplinary methodologies may be required for fully understanding how preferential flow paths contribute to overall transport of water in these environments. The analysis of this study is from the perspective of the usual top-down formulation where recharge dynamics shapes the conceptualization of the island's aquifer system.

\subsection{Poisson surface reconstruction}

Surface reconstruction works by taking unorganized raw input that is lacking orientation and structure information and locally defines from this information the topology of the underlying shape. Poisson reconstruction was selected for the purposes of this study because it defines surface reconstruction in terms of the elliptic Laplace-Beltrami operator and because of the algorithm's well-established credibility as a computationally robust algorithm for surface reconstruction in computer graphic rendering. It is worth mentioning that there are many different approaches to performing surface reconstruction. There are methods which range from assuming well-sampled point clouds to methods that make loose assumptions regarding the quality of the point cloud. In this presentation, Poisson surface reconstruction is believed to allow for authentic analysis of the physical phenomena influencing the behaviour of the karst system because physical phenomena are generally modelled using elliptic operators that relate to some specific parameter of the phenomena. For example, the elliptic operator as expressed in eqn (1) 


$$
\mathcal{L}=\frac{\partial}{\partial x_{1}}\left(a \frac{\partial}{\partial x_{1}}\right)+\frac{\partial}{\partial x_{2}}\left(a \frac{\partial}{\partial x_{2}}\right)=\nabla \cdot(a \nabla)
$$

may be used to determine the scalar function $(\alpha)$ for some specific parameter such as density or porosity of a medium. A similar expression, shown in eqn (2), may be used in the case where the medium is anisotropic and inhomogeneous:

$$
\mathcal{L}=\frac{\partial}{\partial x_{1}}\left(a_{1} \frac{\partial}{\partial x_{1}}\right)+\frac{\partial}{\partial x_{2}}\left(a_{2} \frac{\partial}{\partial x_{2}}\right)=\nabla \cdot(\vec{a} \cdot \nabla),
$$

where the coefficients $\alpha_{1}$ and $\alpha_{2}$ are dependent on the space variable and are reflective of the position and directional nature of the material properties of the medium. The case where the medium is unconfined and anisotropic is expressed by eqn (3):

$$
\nabla \cdot(\vec{K} \cdot \nabla h)=0 \cdot
$$

Poisson surface reconstruction is formulated on the notion that the normal field of the perimeter of an object may be taken to represent the slope pertaining to the object's indicator function [18]. According to the study by Kazhdan et al. [18], starting from a collection of oriented points sampling the boundaries of an object, a 3D mesh may be constructed by converting the discrete oriented point sample into a continuous vector field in three dimensions. Using this idea, Pardo-Igúzquiza et al. [11] showed that surface reconstruction from oriented points may be expressed as the solution to a spatial Poisson problem using the following eqn (4):

$$
\Delta \chi \equiv \nabla \cdot \nabla \chi=\nabla \cdot \vec{V}
$$

Poisson formulation, as defined by eqn (4), may be interpreted as approximating a scalar indicator function $(\chi)$ of some inferred solid. The algorithm itself reconstructs a 3D solid $(\varphi)$ by observing that $\Delta \chi$ should match the normal field $N$ at $\delta \varphi$, where $\delta \varphi$ represents the surface. In general, this process is done by first recovering a scalar function with slopes that closely correspond to the vector field. Next, the correct isosurface is extracted. This process inverts the gradient operator and finds $\chi$ by solving Poisson equation. Poisson-generated surfaces are described as displaying varying levels of detail that is dependent on the input of the octree depth. An octree is a regular hierarchical spatial data structure used in computer graphics algorithms and solid modelling to render point clouds in real time and to reduce the load times [19]. The octree depth is defined as the largest extent of the tree that can be utilized for performing surface reconstruction and is a measure of the amount of detail in that region of the shape. Poisson reconstruction first transforms an oriented point cloud sampling of an object into a continuous vector field in 3D. Then, it finds a scalar function $\chi$ whose gradient best approximates the field. Finally, an isosurface is extracted from this information. The scalar function $\chi$ is found by minimizing $E(\chi)=\int \nabla \chi(p)-\vec{V}(p)^{2} d p$. The minimum is found by solving the Poisson equation using Galerkin method. The isosurface may be extracted by defining the model as a level set of a scalar function $\chi: U \rightarrow \mathbb{R}$, where $U \subset \mathbb{R}^{3}$ is the domain of the volume and the range of the surface model. From this definition, a surface $\boldsymbol{Z}$ may be defined as $\boldsymbol{Z}=\{x \mid \chi(x)=k\} . \quad k$ is called the $k$-value associated with the isosurface $\chi(x)$. The value of $k$ is arbitrarily chosen, such that the surface normal of the isosurface is given by the normalized gradient vector. Normally, a surface normal is associated with a point in the volume domain $U$, such that $n(x)=\frac{\nabla \chi(x)}{|\nabla \chi(x)|}$ and $x \in U$. 


\section{DATA PRESENTATION, ANALYSIS, AND INTERPRETATION}

Areas within a karst system may become active, or drain, depending upon the nature of a rainfall event. As a result, it was decided that this investigation needed to be conducted in two stages: one stage for data collected during the dry season and the second stage for data collected during the wet season. Doing these separate studies gives the opportunity to visualize any seasonal changes to the storage of the island's aquifer observed. Being able to easily visualize possible fluctuations in the aquifer storage may aid in potentially predicting regions where contaminants may become trapped or lodged. And, it may also aid with providing an improved capability of defining regions of activity or inactivity within the aquifer, depending on the island's seasonal weather patterns. Future works are planned to perform another surface reconstruction on point cloud data collected during the wet season, in order for comparison with the results of the dry season data used in this present study. Table 1 provides a highly condensed sample of the raw data used for this study.

Table 1: Summary data from Barbados' limestone aquifer sampled to the depth of the water table.

\begin{tabular}{lll}
\hline Easting $(\mathbf{E})$ & Northing $(\mathbf{N})$ & Elevation $(\mathbf{f t}$. a.s.l) \\
\hline 20,723 & 88,379 & 132 \\
20,838 & 88,389 & 126 \\
20,508 & 87,659 & 137 \\
58,220 & 58,900 & 395 \\
56,410 & 59,050 & 142 \\
58,038 & 62,830 & 615 \\
57,980 & 62,550 & 560 \\
\hline
\end{tabular}

Raw data sample: well log data from Barbados' limestone aquifer

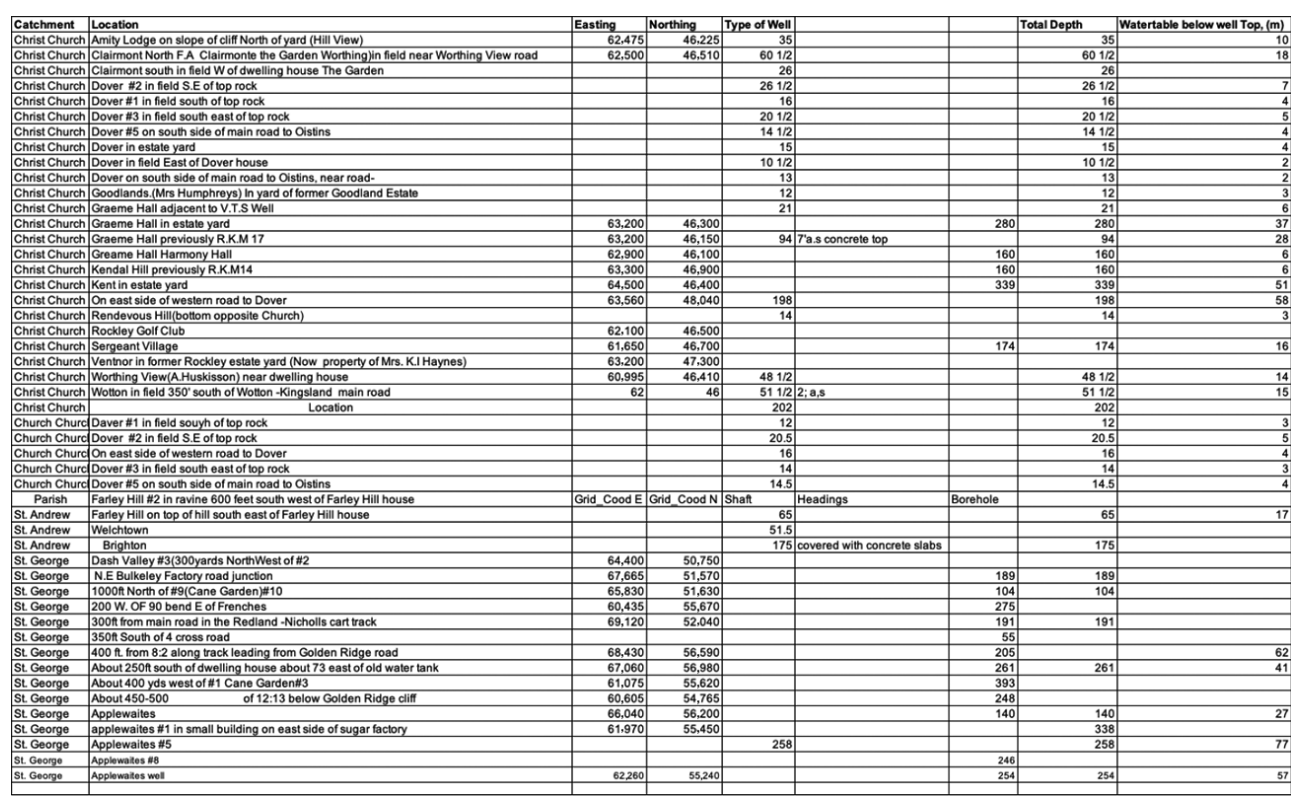


A fundamental assumption behind using the proposed surface reconstruction technique was the mimicking characteristic of the water table. Recall that assumption made to construct this model was that the water table exhibited a general mimicking characteristic of the topology of the land surface above it. To ensure that this assumption was valid, a test had to be conducted to verify that the environment under investigation was one where the water table was mimicking the surface topology. For this testing phase of the study, an adapted version of Voronoi/Delaunay surface reconstruction algorithm that is a routine of the software tool called 'ROOT' was used to interpolate the point cloud data set. The ROOT modelling system is an 'object-oriented framework' that is capable of generating 3D visualization for visual analysis and is widely used in fields such as astrophysics, neural network applications, medical imaging, and business applications $[22,44]$. The ROOT system has the advantage that instead of having to write graphics routines, or modify existing programs, a framework provides the user with graphic functions and routines that have been already well tested. This prepacked facility provided a large class of routines that can be immediately applied to the data set without the need for user-written programs. For example, the Delaunay refinement functions and routines in ROOT that were utilized in this research to perform the surface reconstruction of the aquifer system is a mesh generation technique built upon a well-known geometric structure known as the Delaunay triangulation algorithm. The Delaunay triangulation algorithm of ROOT incrementally develops an interpolation of the surface by utilizing the surface-oriented properties associated with the given data points [23]. It does so by removing interior facets, so as to produce the final triangulation of the surface. This type of formulation interpolates a point cloud without the need for obtaining extra information pertaining to surface normals or scanner data. Because surface reconstruction equates to establishing connections between samples that are neighbours on the surface, any geometric construction defining a simplicial complex on these samples is considered a candidate auxiliary data structure for reconstruction. Because of its ability to code the neighbouring relations in any direction, Delaunay triangulation is considered an ideal choice for the first approximation analysis intended in this research. Particularly, the Delaunay method is known to provide clues to the geometric and topological nature of the reconstructed surface, once there is a dense enough input sampling. However, the main disadvantage of Delaunay triangulation routines is that they assume that the point cloud is noise free and constructs triangular meshes that interpolate all or most of the points. Practically, the sampling point cloud data is often noisy due to sampling inaccuracy. Since Delaunay formulations emphasize that the point cloud is noise free, they are considered impractical in real-world applications where data is expected to be noisy. Noisy data cause Delaunay-reconstructed surface to be jagged. However, since for this part of the study, the focus was on verifying that the model was correctly calibrated in the sense that the water table was mimicking the general topology of Barbados, no refinements were made to the initial Delaunay reconstructions.

Lace and Mylroie [24] conducted various studies of Barbados' karst environment. According to them, the island of Barbados should feature a groundwater distribution that is mound shaped with the highest point near the geographical centre of the island and extends towards the coastline where it thins. This observation by Lace and Mylroie about the general groundwater distribution of Barbados was used for comparative purposes. Figure 5 shows the result of the surface reconstruction applied to the input data. Figure 5 appears to be in agreement with the observation made by Lace and Mylroie about the general groundwater distribution characteristic of the island. It depicts the island of Barbados as having the highest concentration of groundwater approximately central of the island and thins in directions extending 


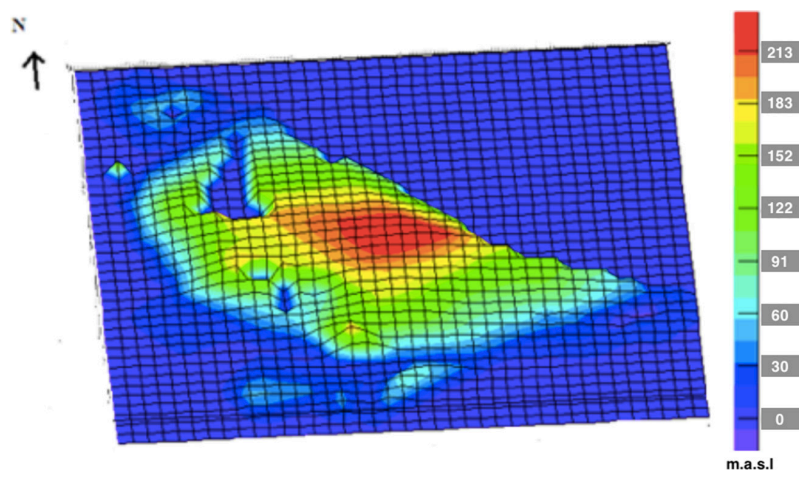

Figure 5: Delaunay surface reconstruction showing mimicking characteristic of Barbados' water table.

towards the coastlines. As this initial test of the reconstruction reproduced similar results to those of Lace and Mylroie [24], the original model assumption about the mimicking characteristic of the water table was accepted as valid. In addition, the result was also perceived as a good indication that the surface reconstruction approach most likely was capable of correctly modelling the internal structures of Barbados' karst aquifer and potentially adding a different or new perspective to the well-established Composite Karst Model (CIKM) classification of the island of Barbados [20-21].

Given the limitations of Delaunay surface reconstruction, the more robust and highly revered Poisson surface reconstruction was applied to the same data set of Fig. 1 to ascertain whether this technique could produce a $3 \mathrm{D}$ image of the internal structure of the aquifer. Specially, the objective was to determine whether the more robust Poisson algorithm would enhance the model's capacity to reconstruct the distinct types, patterns, and segments of flow associated with the basic genetic settings of Barbados' karst. For this part of the study, the Poisson surface reconstruction algorithm that is a part of the open source modelling program MeshLab was used. MeshLab is considered a hi-tech mesh processing system that accommodates both automatic and user sustain editing, cleaning, filtering, converting, and rendering of large, unstructured 3d triangular meshes. Using another already well-established modelling application meant rewriting graphic routines where unnecessary. Particularly, the model was tested to determine its feasibility in the use of extracting visual clues of the backbone or feedback mechanism associated with Barbados' karst aquifer. Figure 6 shows the result of implementing Poisson surface reconstruction to point cloud data sampling Barbados' karst aquifer. To potentially interpret Fig. 6, the distribution of recharge water to the island's karst aquifer was considered. The real limestone aquifer, which Fig. 6 is meant to characteristically depict, is composed of several components. The characteristic size of conduits may vary and allow flow across a network and the matrix itself. It is reasonable to expect that in a karst aquifer, some conduits are interconnected to form a network and others are not interconnected and form 'dead ends'. Dead ends, for the purposes of this study, are conduits that may contain stagnant fluid and do not allow flow through them. Presumably, the observed structure in Fig. 6 may be a result of the flow dynamics of the aquifer itself. For example, it is likely that due to the composition of the aquifer, parcels of fluid are likely to travel different distances over the same time period. Additionally, because the aquifer will contain several flow paths with different resistances to fluid flow, it is reasonable to expect different speeds 


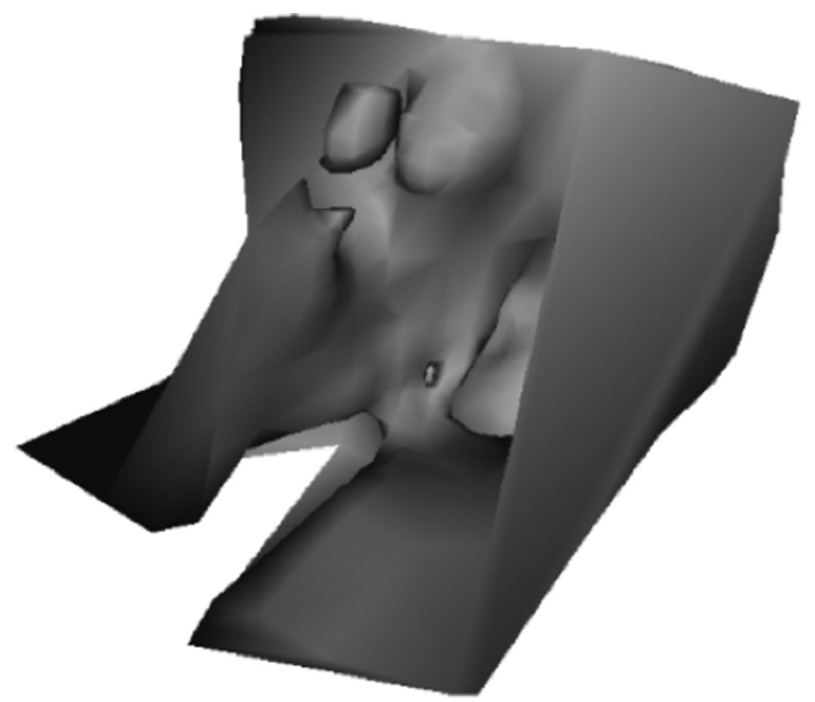

Figure 6: Poisson surface reconstruction depicting the interior of Barbados karst aquifer.

for fluid in various components of the medium, and hence, these different speeds will cause spreading out of flow in time after travelling some arbitrary distance.

Based on Fig. 6, one may want to know if spreading occurs in this system at a constant rate; and if so, how rapidly? How sensitive is the spreading to any variation in system size or structure? As valid these questions may be, for the present analysis, they are considered immaterial for this proof-of-concept study. What is considered important for this particular investigation is establishing whether Fig. 6 is a reasonable representation of the island's underground drainage system, given what is already known about the geology and hydrogeology of Barbados. However, to do this requires further investigation. Such works are planned for a future study. The assumption behind that future investigation will be that cave type and morphology are a consequence of the hydrogeological and geological characteristics of the environment, and as such, cave type and morphology could be used to probably determine the conditions under which the conduit-like structure of Fig. 6 developed. In that study, an attempt will be made to quantify the lacunarity and complexity of the structure in Fig. 6 using fractal analysis. Fractal analysis will provide the opportunity to better describe the results of this study in terms of the complexity of reconstructed surface's structure and its relation to the space it occupies. For example, fractal analysis can be used to further investigate the results of this study, since it is known that Harrison's Cave and Cole's Cave stream caves, as previously mentioned, are examples of the conduit systems of Barbados. And, stream caves usually form in regions where there are connections between non-carbonate basement rock and overlying carbonate rock, where allogenic recharge feeds a cave stream that rests on the non-carbonate basement rock. Stream caves are formed by freshwater dissolution generated as a consequence of epigenic recharge and usually feature branching drainage patterns [26-28]. The complexity of stream cave patterns ranges between that of the littoral pattern and flank-margin pattern [26]. According to Kambesis et al. [26], the morphology of stream caves is predominately linear, and they have the greatest range in lacunarity. Kambesis et al. also note that increase in stream pattern lacunarity is directly related to an increase in stream fractal dimension. 
However, as this present work is a proof-of-concept study, it is considered sufficient at this point to highlight that the results validate the modelling assumption that applying a surface reconstruction algorithm and solving the Poisson equation over a point cloud taken from a karst aquifer make it possible to interpolate the positive feedback mechanism associated with phreatic conduits of a real karst system. However, it is acknowledged that at this stage of the study, the model does not include analysis for processes such as spring discharge and estimated groundwater residence times. It is understood that these and other processes that may play a significant role in the speleogenesis model deserve further study. Therefore, it is planned in a future study to explicitly show how the hydraulic conductivity values for the matrix, flow boundary conditions, and the topology can be defined from the input point cloud data. Although there is much work to be done in further advancing the approach used in this work, the results of this investigation are considered significant in the case of Barbados with respect to improving the island's water resource management. Water resource managers in Barbados are currently exploring ways of expanding the island's water supply capacity, drainage capabilities, and water management strategies to meet the needs of its people. This research and the planned future studies may be viewed as necessary steps in the island, creating a systematic approach to advancing Barbados' water infrastructure through creating reliable and accurate 3D representation of Barbados' karst aquifer and its karst conduits. Often, the geometrical properties of the conduit network within a karst aquifer system are not well known [30]. It is the geometries of the unknown conduits that dictate how flow moves through the aquifer. The geometrical property of the conduit is described through the characteristics of the conduit cross-section, the geometrical arrangement of passages taken directional to the flow, and the geometrical property of the network itself. It is believed that this work is the first step towards potentially addressing many of the uncertainties surrounding the island's conduit networks.

\section{CONCLUSION}

Identifying conduits and characterizing conduit flow in karst aquifers in their natural environment is difficult. When investigating karst aquifers, both a diffuse and a conduit component must be considered, since the unique feature of a karst aquifer is the rapid response of the conduit system to flow as compared with that of a diffuse aquifer system. Most often, large dimensions of conduits, their interconnections, high water level gradients, and the high permeability of surface zones enable rapid filling and emptying of karst system. A high precipitation rate may fill the conduit system, causing a rapid rise in water level over a relatively short time period. It is extremely important to identify conduits and characterize the conduit flow in the case of Barbados, since fast groundwater flows can occur within karst, and little is known about the interface between the epikarst and underlying conduit networks and, in particular, of the distribution of travel times between the source and exit points for contaminant transport. As a result, a particular concern of water resource managers in Barbados is the potentially short travel time for the migration of contaminants entering the aquifer. To date, a comprehensive description of the complete geometry and topology of Barbados' karst aquifer remains limited and uncertain. Therefore, it is critical and urgent to develop karst aquifer modelling techniques that can provide realistic numerical models of the island's aquifer. Most of the aquifer investigations done on the island have employed techniques such as time-domain electromagnetic soundings, Schlumberger D.C. resistivity depth soundings, high-resolution dipole-dipole profiles for tomographic imaging, and shallow ground conductivity profiles to make the following observations about the island's aquifer. In this paper, 
Poisson surface reconstruction was explored as an additional tool for potentially gaining improved insights into Barbados' aquifer. The results suggest that surface reconstruction applied to data sampled from an aquifer is an efficient method for interpolating the positive feedback associated with the 3D networks of a karst system. As a result, it is concluded that the direct application of surface reconstruction to a karst environment highlights the diversity of surface reconstruction and how it potentially provides a way forward in producing karst aquifer models that are more practical for predicting spatial patterns of conduits in their natural environment.

\section{REFERENCES}

[1] Collon-Drouaillet, P., Henrion, V. \& Pellerin, J., An algorithm for 3D simulation of branchwork karst networks using Horton parameters and A-star: application to a synthetic case. Geol Soc Lond., Spec. Pub, 370(1), pp. 295-306, 2012. https://doi. org/10.1144/sp370.3

[2] Jaquet, O., Siegel, P., Klubertanz, G. \& Benabderrhamane, H., Stochastic discrete model of karstic networks. Adv Water Resour, 27(7), pp. 751-760, 2004. https://doi. org/10.1016/j.advwatres.2004.03.007

[3] Ronayne, M., Influence of conduit network geometry on solute transport in karst aquifers with a permeable matrix. Adv Water Resour, 56, pp. 27-34, 2013. https://doi. org/10.1016/j.advwatres.2013.03.002

[4] Vuilleumier, C., Borghi, A., Renard, P., Ottowitz, D., Schiller A, Supper R. \& Cornaton, F., A method for the stochastic modeling of karstic systems accounting for geophysical data: an example of application in the region of Tulum, Yucatan Peninsula (Mexico). Hydrogeol. J, 21, pp. 529-44, 2013. https://doi.org/10.1007/s10040-012-0944-1

[5] Borghi, A., Philippe, R. \& Cornaton, F., Can one identify karst conduit networks geometry and properties from hydraulic and tracer test data? Adv Water Resour, 90, pp. 99-115, 2016. https://doi.org/10.1016/j.advwatres.2016.02.009

[6] Borghi, A., Philippe, R. \& Sandra, J., A pseudo-genetic stochastic model to generate karstic networks. J Hydrol, 414, pp. 516-529, 2012. https://doi.org/10.1016/j.jhydrol.2011.11.032

[7] De Rooij, R. \& Graham, W., Generation of complex karstic conduit networks with a hydrochemical model. Water Resour. Res., 53, pp. 6993-7011, 2017. https://doi. org/10.1002/2017wr020768

[8] Western, A.W., Blöschl, G., \& Grayson, R.B., Toward capturing hydrologically significant connectivity in spatial patterns. Water Resour. Res. 37, pp. 83-97, 2001. https://doi. org/10.1029/2000wr900241

[9] Filipponi, M., Jeannin, P.Y. \& Tacher, L., Understanding cave genesis along favourable bedding planes: the role of the primary rock permeability, Z. Geomorphology, 54, pp. 91-114, 2010. https://doi.org/10.1127/0372-8854/2010/0054s2-0006

[10] Bonacci, O., Pipan, T., \& Culver, D.C., A framework for karst ecohydrology. Environmental Geology, 56, pp. 891-900, 2009. https://doi.org/10.1007/s00254-008-1189-0

[11] Pardo-Igúzquiza E., Dowd, P.A., Chaoshui, X. \& Durán-Valsero, J.J., Stochastic simulation of karst conduit networks. Adv. Water Resour, 35, pp. 141-150, 2012. https://doi. org/10.1016/j.advwatres.2011.09.014

[12] Pinault, J.L., Bakalowicz, M., Plagnes, V. \& Aquilina, L., Inverse modelling of the hydrological and the hydrochemical behaviour of hydrosystems: characterization of 
karst system functioning. Water Resour. Res, 37, pp. 2191-2204, 2001. https://doi. org/10.1029/2001wr900018

[13] Shaban, A. \& Darich, T., The role of sinkholes in groundwater recharge in the high mountains of Lebanon. J. Environ. Hydrol, pp. 19, 1-11, 2011.

[14] Goldscheider, N., Meiman, J., Pronk, M. \& Smart, C., Tracer tests in karst hydrogeology and speleology. International Journal of Speleology, 37(1), pp. 27-40, 2008. https:// doi.org/10.5038/1827-806x.37.1.3

[15] Kaufmann, G., A model comparison of karst aquifer evolution for different matrix-flow formulations. J. Hydrol., 283(1-4), pp. 281-289, 2003. https://doi.org/10.1016/s00221694(03)00270-1

[16] Kaufmann, G., Modelling karst geomorphology on different time scales. Geomorphology, 106(1-2), pp. 62-77, 2009. https://doi.org/10.1016/j.geomorph.2008.09.016

[17] Kaufmann, G., Romanov, D. \& Hiller, T., Modeling three-dimensional karst aquifer evolution using different matrix-flow contributions. J. Hydrol., 388(3-4), pp. 241-250, 2010. https://doi.org/10.1016/j.jhydrol.2010.05.001

[18] Kazhdan, M., Bolitho, M. \& Hoppe, H., Poisson surface reconstruction. Proceedings of 4th Eurographics Symposium on Geometry Processing, pp. 61-70, 2006.

[19] Aronov, B., Brönnimann, H., Chang, A.Y. \& Chiang, Y.J., Cost-driven octree construction schemes: an experimental study, Computational Geometry, 31, pp. 127-148, 2005. https://doi.org/10.1016/j.comgeo.2004.07.005

[20] Kambesis, P.N. \& Machel, H.G., Caves and Karst of Barbados. In Lace, M.J. \& Mylroie, J.E., eds., Coastal Karst Landforms, Dordrecht: Springer, Coastal Research Library 5, pp. 227-244, 2013.

[21] Stafford, K.W., Mylroie, J.E., Taborosi, D., Jenson, J.W. \& Mylroie, J.R., Karst development on Tinian, Commonwealth of the Northern Mariana Islands: Controls on dissolution in relation to the carbonate island karst model. Journal of Cave and Karst Studies, 67(1), pp. 14-27, 2005.

[22] Klein, A. \& Godunov, A., Introductory Computational Physics, Cambridge University Press, 2006.

[23] Cazalas, F. \& Giesen, J., Delaunay Triangulation-based Surface Reconstruction. In Effective Computational Geometry for Curves and Surfaces, Springer, 2006.

[24] Lace, M.J. \& Mylorie, J.E., Coastal Cave and Karst Resource Management. In Coastal Karst Landforms, Dordrecht: Springer, 2013.

[25] Pardo-Iguzquiza, E., Durán-Valsero, J.J. \& Rodríguez-Galiano, V., Morphometric analysis of three-dimensional networks of karst conduits. Geomorphology, 132(1), 17-28, 2011. https://doi.org/10.1016/j.geomorph.2011.04.030

[26] Kambesis, P.N., Larson, E.B. \& Mylroie, J.E., Morphometric analysis of cave patterns using fractal indices. In Feinberg, J., Gao, Y., \& Alexander, E.C., Jr., eds., Caves and Karst Across Time: Geological Society of America Special Paper 516, pp. 67-86, $2015 \mathrm{a}$.

[27] Palmer, A.N., Distinction between epigenic and hypogenic maze caves. Geomorphology, 134, pp. 9-22, 2011. https://doi.org/10.1016/j.geomorph.2011.03.014

[28] Jameson, R.A., Identification and analysis of early flow paths in branchwork caves in west virginia, usa. Geological Society of America Special Papers, 404, pp. 23-30, 2006

[29] Farrell, D.A., Sandberg, S.K., Mayers, B.L., Sutherland, A., Barnes, H., Nurse, J. \& Moseley, L., Characterizing and Modeling of Seawater Intrusion in an Aquifer along the West Coast of Barbados. EEGS 17th Symposium on the Application of Geophysics to Engineering and Environmental Problems, pp. 1216-12795, 2004. 
[30] Covington, M.D., Wicks, C.M., \& Saar, M.O., A dimension-less number describing the effects of recharge and geometry on discharge from simple karstic aquifers.Water Resour. Res, 45, pp. 1216-12795, 2009. https://doi.org/10.1029/2009wr008004

[31] Taboroši, D., Jenson, J.W., \& Mylroie, J.E., Zones of enhanced dissolution and associated cave morphology in an uplifted carbonate island karst aquifer, northern Guam, Mariana Islands. Speleogenesis Evol. Karst Aquifers, 1(4), pp. 1-16, 2003.

[32] Collon, P., Bernasconi, D., Vuilleumier, C., \& Renard, P., Statistical metrics for the characterization of karst network geometry and topology. Geomorphology, 283, pp. 122-142, 2017. https://doi.org/10.1016/j.geomorph.2017.01.034

[33] Cashman, A.C., Water Policy Development and Governance in the Caribbean: An overview of regional progress. Water Policy, 14(1), pp. 14-30, 2012. https://doi. org/10.2166/wp.2011.122

[34] Doerfliger, N., Jeannin, P.Y. \& Zwahlen, F., Water Vulnerability Assessment in Karst Environments: A new method of defining protection areas using a multi-attribute approach and GIS tools (EPIK method). Environmental Geology, 39(2), pp. 165-176, 1999. https://doi.org/10.1007/s002540050446

[35] Foster, S. \& Skinner, A.C., Groundwater protection: The science and practice of land surface zoning. IAHS Publications-Series of Proceedings and Reports-Intern Assoc Hydrological Sciences, 225, pp. 471-482, 1995.

[36] Onody, R.N. \& Zara, R.A., Cluster, backbone, and elastic backbone structures of the multiple invasion percolation. Physical Review E, 56(3), pp. 1063-6510, 1997. https:// doi.org/10.1103/physreve.56.2548

[37] Berkowitz, B. \& Balberg, I., Percolation theory and its application to groundwater hydrology. Water Resources Research, 29(4), pp. 775-794, 1993. https://doi. org/10.1029/92wr02707

[38] Jacobsen, L.J. \& Zinn-Justin, P., Monochromatic path crossing exponents and graph connectivity in 2D percolation. Phys. Rev. E. 66(5), pp. 1-3, 2002a. https://doi. org/10.1103/physreve.66.055102

[39] Jacobsen, L.J. \& Zinn-Justin, P., A transfer matrix for the backbone exponent of twodimensional percolation. J. Phys. A: Math Gen., 35, pp. 2131-2144, 2002b. https://doi. org/10.1088/0305-4470/35/9/304

[40] Ali-Bray., N., Moore, J.E., Senthil, T., and Vishwanath, A., Ordering near the percolation threshold in models of two-dimensional bosons with quenched dilution. Physical Review B, 73(6), pp. 1-10, 2006. https://doi.org/10.1103/physrevb.73.064417

[41] Song, C., Halvin, S. \& Makse, H., Origins of fractality in growth complex networks. Nature Physics, 2(4), pp. 275-281, 2006. https://doi.org/10.1038/nphys266

[42] Mohammadi, Z. \& Raeisi, E., Hydrogeological uncertainties in delineation of leakage at karst dam sites, the Zagros Region, Iran. Journal of Cave and Karst Studies, 69(3), pp. 305-317, 2007.

[43] Jones, I.C. \& Banner, J.L., Estimating recharge thresholds in tropical Karst Island Aquifers: Barbados, Puerto Rico and Guam. Journal of Hydrology, 278(1), pp. 131-143, 2003. https://doi.org/10.1016/s0022-1694(03)00138-0

[44] Antcheva, I., et al., ROOT: A C++ framework for petabyte data storage, statistical analysis and visualization. Comput. Phys. Commun., 182(6), pp. 1384-1385, 2011. https:// doi.org/10.1016/j.cpc.2011.02.008 